\title{
A critical appraisal of WinEcon and its use in a first-year undergraduate Economics programme
}

\author{
D. J. Brooksbank, A. Clark, R. Hamilton and D. G. Pickernell \\ The Business School, University of Glamorgan. Email: aclark @@glam.ac.uk
}

This is an extended review of WinEcon, a CAL package for introductory economics. Our comments are based on a survey of staff and students involved in the first large-scale $(n=$ $300+$ ) attempt to integrate WinEcon into a teaching and assessment programme.

\section{The WinEcon project}

WinEcon is a Windows-based introductory Economics CAL package designed for use in higher education. It is the product of the Economics Consortium of the TLTP (Teaching and Learning Technology Programme) consisting of eight university Economics departments. Each of these has been responsible for producing some of the 25 chapters (tutorials) of the finished product. Content is based on covering the common core of introductory Economics as revealed by a survey of higher-education Economics departments. WinEcon is provided, with an accompanying workbook, for a nominal registration fee in the UK. The package is important insofar as it is aimed at all first-year undergraduates studying Economics, which encompasses not only those taking straight Economics degrees but large numbers of students following introductory Economics as part of a Business Studies or Combined Studies course. With no competition to speak of, WinEcon is likely to become a significant feature of the learning experience of a large tranche of the undergraduate population, across a number of degree schemes. Indeed, for many of these students WinEcon will constitute their first major experience of CAL.

\section{Integrating WinEcon}

It is intended that WinEcon, like all TLTP products, should be integrated into teaching programmes to such an extent that it becomes an indispensable learning resource. Although, as Jacobs (1996) points out, TLTP products have had less success in this aim than was hoped, we decided from the outset to give WinEcon a central role in our curriculum by locating it within a cycle of 'wanting, doing, feedback, and digestion' (Race, 1994). The initial motivation would come from our pioneering use of WinEcon's 
and what the learning objectives are. None of these is a feature of WinEcon. This may be a sin of omission, but it could also be that, with few words to play with, making links may have been seen as a luxury that the authors could not afford. It would then be an understandable, but none the less significant, sin of omission, and would, again, be indicative of the difficulties entailed in putting a textbook on a screen. It may also reflect the fact that with many authors working in relative isolation, the co-ordination of ideas may have become onerous. In addition, the lack of interaction in WinEcon means that the only effective control students have over their learning is to adjust the pace at which they work through the text. This is a type of control, but it does not involve the level of control and of mutual re-adaptation that experienced teachers use in a tutorial setting. So, although WinEcon is referred to as a tutorial system, what it provides does not equate to our current tutorial practices, or the definitions of such that are used in educational literature. For example, for Laurillard (1993, p. 152) the key feature of a tutorial is adaptation, hence to imitate this a package needs to use 'the students' performance on previous tasks to decide what tasks should be set next, without which it is not a tutorial'. Programs that do this are often referred to as 'intelligent teaching programs'. Creating this kind of 'intelligence' requires not just subject knowledge but also an understanding of how students learn, an aspect of the production of effective CAL that we feel has been largely overlooked in the WinEcon case. These criticisms are supported by students' feedback, for despite the fact that WinEcon is referred to as a 'tutorial program', 81 per cent of students did not believe that it should replace classroom tutorials.

Our third reason for believing that WinEcon could lead to enhanced learning was that it would add to variety in the learning experience by providing something that might otherwise not have been available, given institutions' reluctance to invest in CAL. WinEcon lived up to expectations in this respect: it is colourful and well written, so that 57 per cent of students felt that it explained difficult topics well.

Finally, we envisaged the possibility that improved learning could result directly from the freeing of staff time that substitution by machine could produce, since this time would have been used for educational development. Although few such benefits have materialized as yet, we anticipate that benefits of this kind will do so in future as we (and the programmers of WinEcon) move along the learning curve in applying this package.

\section{Conclusions}

We found that WinEcon was welcomed as an additional source of information by students, but it did not provide the level of learner interaction or learner control that staff had anticipated, which - once the novelty had worn off - led to student dissatisfaction too. To understand its failings in terms of the learning process, we need to consider the pedagogical philosophy underlying WinEcon: the lack of interaction, the form of the interaction, the linearity of the discourse, and the overall pedagogical style of the package are indicative of a 'transmission of knowledge' approach to teaching, where unproblematic information - that exists sui generis - is transmitted to the receptive student, so that 'content knowledge and fluent presentation are enough for good teaching' (Ramsden, 1991, p. 116). This approach tends to play down the importance of barriers to learning, such as students' misconceptions, and largely ignores their ex ante understandings of topics, and how they integrate the information; in short, how they learn. 
In contrast, we believe a well-designed package should reflect what has been learned about the way students learn, and be responsive to their current conceptions of the subject matter. As Laurillard (1994, p. 187) argues: 'it is impossible for teaching to succeed if it does not address the current forms of students' understanding of a subject'. This understanding will enable the author to engage in a dialogue with the learner and incorporate programmed responses to misconceptions if they arise. To incorporate all possible misconceptions in a computer program may seem an impossible task, but these misconceptions are not random, or necessarily extensive, as knowledge and understanding are constructed in well-researched psychological and social contexts. Moreover, the student interfaces with a relatively static body of knowledge at this level in Economics, in a process that is replicated in many institutions, and within the same institution time after time. The result is plain from discussions of shared experience among Economics lecturers: there are a few key recurring misconceptions that are encountered in teaching introductory Economics. Moreover, many of these have been identified in the educational literature (see, for example, Dahlgren, 1984). None of the main ones that have been identified are addressed in WinEcon, which may help to explain why so many students felt that a teacher's presence was needed when using it, and why heavy use was made of the teachers who did supervise the sessions.

The type of feedback provided by WinEcon is also indicative of the transmission approach in two respects. First, there is the predominant use of multiple-choice questioning, which is typical of the transmission approach as it serves to check that the message has been received. Such assessment is based on how much, and how accurately, information is known rather than what is understood, whereas a more student-centred approach focuses on what is understood and is typically assessed using case studies, reports, and problemsolving tasks. Using the typology of MacDonald et al. (1976) quoted in Somekh (1996), we argue that WinEcon seldom goes beyond the recognition and recall types of interaction, and thus provides little 'constructive' learning. Secondly, the feedback in WinEcon is of the 'No, because ... .' (or often just plain 'No') type commonly referred to as extrinsic feedback. The problem with this is that, again, it fails to address conceptual misunderstanding, as Laurillard (1993) argues. To uncover misunderstanding, intrinsic feedback is necessary as well, that is feedback that arises not as a description of the appropriateness of an input, but rather as the product of the interaction with the conceptual model to the extent that the learning process is conditional on that input. Learning is then experienced from interaction with the conceptual model being taught rather than descriptions of it.

We recognize that in the case of introductory Economics, the learning process cannot be individualized to the extent that the student determines what Plowman (1992) calls the 'path of disclosure', as this can obscure the prerequisite nature of consecutive ideas, and * use of terms, in this subject area. However, as Entwistle and Ramsden (1983) show, teaching shapes students' approaches to learning, even their meta-cognitive strategies. So, to the extent that the student's approach to the learning process is malleable and conditional on the context, WinEcon will reinforce desires for a linear, non-discursive, approach. Indeed research with a sub-group of students employing a deep-learning approach (cf. Marton and Saljo, 1976; 1984) showed that they became more dissatisfied with WinEcon than other students, and tended to resort to flicking through pages. This lack of interest is atypical of such a group whom we would expect to engage relatively 
deeply with the subject matter and maintain high levels of interest, and academic success (see van Rossum and Schenk, 1984; Trigwell and Prosser, 1991; Watkins and Hattie, 1985).

Our responsibility in conducting this review is to appraise the likely returns to investing in WinEcon, for although it is essentially free of charge to users, we must consider the time, effort, and associated opportunity costs, as time spent using WinEcon is time not spent engaged in other learning activities. In doing this, we recognize that CAL is not a panacea for all teaching in the future. None the less, we have to report that both staff and students found WinEcon uninspiring. This is a pity, since for many students it means that their first major experience of CAL is unlikely to be a happy one.

\section{References}

Dahlgren, L. O. (1984), 'Outcomes of learning' in Marton, F. et al. (eds.), The Experience of Learning, Edinburgh: Scottish Academic Press.

Entwistle, N. J. and Ramsden, P. (1983), Understanding Student Learning, London: Croom Helm.

Feifer, R. and Allender, L. (1994), 'It's not how multi the media is, it's how the media is used', ED-MEDIA Conference Proceedings, Vancouver, Canada.

Hall, R. E. and Taylor, J. B. (1986), Macroeconomics, London: W. W. Norton.

Jacobs, G. (1996), Editorial in $A L T-J, 4$ (3).

Laurillard, D. (1993), Rethinking University Teaching: A Framework for the Effective Use of Educational Technology, London: Routledge.

MacDonald, B. et al. (1976), 'The educational potential of computer-assisted learning: qualitative evidence about student learning', UNCAL, CARE, UEA.

Marton, F. and Saljo, R. (1976), 'On qualitative differences in learning', British Journal of Educational Psychology, 46, 4-11.

Marton, F. and Saljo, R. (1984), 'Approaches to learning' in Marton, F. et al. (eds.), The Experience of Learning, Edinburgh: Scottish Academic Press.

Moyse, R. (1991), 'Multiple viewpoints imply knowledge negotiation', Interactive Learning International, 7, 21-37.

Plowman, L. (1992), 'An ethnographic approach to analysing navigation and task structure in interactive multimedia; some design issues for group use' in Monk, A., et al. (eds.), People and Computers VII: Proceedings of HCI 92, Cambridge: CUP.

Race, P. (1994), The Open Learning Handbook, London: Kogan Page.

Ramsden, P. (1991), Learning to Teach in Higher Education, London: Routledge.

Somekh, B. (1996), 'Designing software to maximise learning', ALT-J, 4 (3), 4-16.

TLTP (1993), Module Descriptions: Educational Style Guide, TLTP Publications.

Trigwell, K. and Prosser, M. (1991), 'Relating approaches to study and quality of learning outcomes at the course level', British Journal of Educational Psychology, 61, 265-75. 
van Rossum, E. J. and Schenk, S. M. (1984), 'The relationship between learning conception, study strategy and learning outcome', British Journal of Educational Psychology, 54, 73-83.

Watkins, D. A. and Hattie, J. (1985), 'A longitudinal study of the approach to learning of Australian tertiary students', Human Learning, 4, 127-42. 